\title{
Various Views of Dependency from the Perspective of Definitions
}

\author{
Zhixiu Zhang \\ College of International Studies, Southwest University, Chongqing, China \\ Email: zedan35@163.com
}

Received 18 May 2015; accepted 19 June 2015; published 24 June 2015

Copyright (C) 2015 by author and Scientific Research Publishing Inc.

This work is licensed under the Creative Commons Attribution International License (CC BY).

http://creativecommons.org/licenses/by/4.0/

(c) (i) Open Access

\begin{abstract}
Focused on the definitions of dependency, the author illustrates that there are various views of dependency from the dependency theory of Tesnière to the modern cognitive linguistics. The followers of Tesnière only study dependency from the perspective of the relations between words, but Tesnière is to research the intrinsic nature of languages, so Tesnière' dependency theory is necessary to be further studied.
\end{abstract}

Keywords

Dependency, Definition, Nature, Relation

\section{Introduction}

The term of dependency firstly appeared in the field of syntax is in the thirteenth century (Percival, 1990), but the definition of dependency is various, there is no one of a unified view about dependency. Tesnière Lucien is generally accepted as the founder in the theories of dependency grammar. The basic view of Tesnière about dependency grammar is early illustrated in Comment construire une syntaxe in 1934 (Tesnière, 1934), the main idea of dependency is reflected in the book of Basic Structural Syntax in 1959 (Tesnière, 1959).

Tesnière emphasizes the necessity of researching on the internality of language put forward by Humboldt; Tesnière proposes that language research should devote much attention to the activity of language; he also advocates that the research of structural syntax should be carried on from the functional and dynamical perspective. Tesnière divides syntax research into static and dynamic research, the basis of static research is the research of vocabulary categories, but dynamic research is focused on the function of vocabulary. Tesnière takes a sentence as an organic holistic whole and dependency as the intrinsic organic connector of the whole. That is, Tesnière makes research on dependency from the nature of a language, but his followers study dependency only from the relations between components and composite structures, they do not touch on the nature connector of a language. 
The basic idea of Tesnière is definitely different from that of the followers in the field of research on dependency.

\section{Dependency in Dependency Research}

Here we think that there are four kinds of perspectives to study dependency in the field of dependency theories (excluding Tesnière), that is, the scholars study dependency from these domains of vocabulary, syntax, semantics, and function. Of course, such kind of classification is just focused on the research interesting of these scholars on dependency; their research perspective strictly is not a kind of clear dichotomy.

\subsection{Dependency on Vocabulary}

A quite number of scholars focus on lexical categories to define and study dependency. Maxwell (1995: p. 8) gives a definition to dependency as this: If the word B is a necessary condition for word A, then the word A is the subordinate component of word B. Hypernym dominates its subordinate component, or it becomes the governor of the latter word. Maxwell takes dependency as a kind of established relationship: if one word is a governor, another word inevitably is the dominated component. But the scope of his research is only limited in some linguistic structures of a language; Hudson and Hellwig extend the substantial limitation of such kind of research scope.

Hellwig (2003) considers dependency as a kind of relationship between a central word (head) and its complement, but Hudson (1980) regards dependency as a relation between the framework of words and its groove. Hudson thinks that dependency is not merely a part of elements of sentences, but also every word has a connective relationship with other words in sentences. Jung thinks that dependency is not just a kind of relation, i.e., a kind of dominating and dominated relation.

Jung (1995) puts forward that dependency includes the two kinds of dominating (Rektion) and restricting (Determination) relation. It is a dominating relation when the head words (Köpfe) open a vacancy for its subordinate component; it is a restricting relation when the subordinate components open a vacancy for its head word. To a certain extent, the interpretation of dependency from Jung reflects the definition of dependency as "an arbitrary directed co-occurrence" put forward by Engel (Engel, 1982: p. 32).

With Jung and Engel, dependency is essentially a kind of directed co-occurrence relation, but not a kind of sequence or established relation. Hudson (2004) takes dependency as a kind of relation between a word and its subordinate component (dependents), and thinks that dependency is a kind of asymmetric relationship.

\subsection{Dependency on Syntax}

Some scholars do their research on dependency from the perspective of syntactic categories. Schubert (1987) constructs a system of dependency parsing for machine translation; dependency is taken as the basic relation of the parsing. He defines dependency as "directed co-occurrence", but here "co-occurrence" in the definition essentially describes the syntactic distribution of sentences. Such kind of syntax relationship is short of the consideration of intended meaning, the definition is different with that of Engel (1982).

Van Valin (2001) considers that two or more elements can be formed as a kind of dependency relation if they coexist in a syntactic structure (arrangement). Van Valin takes syntax as the root of a language, i.e., syntax inherently belongs to a language, but dependency is taken as a kind of embedding relation in an established syntactic structure.

However, Ágel and others define dependency as the conception of grammar, i.e., the words in a sentence are coupled together based on the interconnection of meaning (Ágel et al., 2003: p. XI). Obviously, Ágel et al. believe that dependency is existed in order to manifest the meaning of linguistic expressions.

Syntactic research about dependency is a kind of analysis method of language; such kind of research is inclined to pragmatism, the so-called "utility" is mainly in the two fields: language teaching and natural language computer processing.

\subsection{Dependency on Semantics}

Some scholars mainly research dependency from the perspective of semantics. Kreps (1997) thinks that there exist three kinds of dependency: structural dependency, semantic constraint, and formal constraint. But the determining factors to confirm the three kinds of dependency are not the same. Structural dependency is strictly 
talked about the distributional co-occurrence between elements; semantic constraint is limited to study the connection between words; form constraint is focused on the study of grammatical means or grammatical relations.

Mel'čuk (1988) is more concerned about the meaningful connection between elements. Mel'čuk (2003: pp. 188-229) divides the transverse combination dependence of word form into three kinds of categories: semantic dependency, morphological dependency and syntactic dependency. Mel'čuk thinks that the base of morphological dependency is apparently the form of sentences; the base of semantic dependency is the meaning of sentences; but syntactic dependency is too abstract to define, because it is no direct relationship with the form and meaning of a sentence.

Percival (1990) thinks that there are only syntactic dependency and semantic dependency in a sentence. In the field of semantic dependency, the appearance of some words is just for the limitation of the meaning of others, such idea promotes the development of the concept of dependency. Similarly van Langendonck (2003: pp. 170-187) discusses dependency from the perspective of semantics and syntax. He thinks that dependency is generally available to be analyzed and classified from the perspectives of positive (active) and negative (passive), such method is not only applicable to the head but also the subordinate component (dependent) in a sentence.

\subsection{Dependency on Function}

There are a few scholars to study dependency focusing on the functions of the phrasal structures or sentences. For example, Shaumyan (1987) thinks that dependency is not just the relation between words, but the relation of the functional units of languages. Shaumyan uses dependency and valence to describe the universal structures of human languages, in nature, he reveals that dependency and valence belong to the universal attribute of languages. Hajičová/Sgall (2003: 571) also thinks that the automatic processing of a natural language would be accurate if describing the form and the nature of the language is based on the role of dependency. That is, they emphasize that studying dependency should be taken from the perspective of function of languages.

These scholars illustrate that dependency is not only the necessity of describing phrasal structures, but also the necessity of describing sentences. In fact, they want to reveal that dependency is the root spirit of human languages. Such kind of perspective to study dependency is closer with the idea of Tesnière, but these studies still do not deeply involve the nature of a language.

\section{Dependency in Cognitive Linguistics}

The above research on dependency seemly reveals the relation bounded up with the meaning, but owing to lack of appropriate and sufficient interpretation on the semantic structure, also semantic is very naturally taken as the grammatical category, the scholars on dependency strictly focus their studies on the classification of vocabulary (for example Allerton 1982), i.e., the dependency theories is strictly a kind of static research, not dynamic research. The fundamental reason is that they take vocabulary as the basic units of a language; such kind of studies is beyond the main idea of Tesnière.

Langacker $(1987,2008)$ makes his research on dependency from dynamic perspective; cognitive entities (thing and relation) are taken as the fundamental units of a language in cognitive grammar. Langacker thinks that the classification of words is for understanding the grammar behavior based on deep analysis, deep analysis clearly describes the internal structures and their integration essences of the participate components in linguistic expressions. He thinks that dependency and autonomous is used to describe the intrinsic relationship between components or composite structures, i.e., certain structures require other structures to support, it cannot stand alone in nature, such kind of structure is typically a dependent structure (Langacker, 2008: p. 199). Owing to Langacker thinks that syntax relation in traditional theories essentially is semantic relation, he puts forward that dependency only exists in the semantic and the phonological poles. The intrinsic connection between autonomous and dependent components is called as A/D-alignment; it "is a general feature of language design" (Langacker, 2008: p. 199).

Croft (2001: 175) also thinks that the so-called syntactic relation in traditional construction theories actually is a kind of semantic relationship; syntactic relation is divided into collocational dependence relation and coded dependence relation. The former refers to the selective restriction of one word to another in a sentence (Croft, 2001: 179), the restriction is to limit the possible combinations of words, and the combination is only decided by the conceptual semantic denoted by the words. The latter is syntactic relation that is manifested by the overt aspect of grammatical structure of an utterance (Croft, 2001: p. 176); coded dependencies essentially are se- 
mantic relations.

\section{Conclusion}

This paper has demonstrated that there are various views on dependency from the dependency theories to cognitive linguistics, but all of the scholars in dependency theories do not touch on the root of dependency. Langacker and Croft focus on the semantic of words to illustrate dependency, but they just take dependency as the semantic relations between the components or composite structures, rather than base on the intended meaning to research dependency, that is, they do not research dependency based on the intrinsic nature of a language. All of these views are beyond the idea of Tesnière whether in dependency theories or in cognitive linguistics. So the theory about dependency found by Tesnière is necessary to be further studied, because the root idea of Tesnière is not explored by the followers in the area of dependency research.

\section{References}

Ágel, V., Eichinger, L. M., Eroms, H.-W., Hellwig, P., Heringer, H. J., \& Lobin, H. (Eds.) (2003). Dependenz und Valenz (Volume I). Berlin/New York: Walter de Gruyter. http://dx.doi.org/10.1515/9783110141900.1

Engel, U. (1982). Syntax Der Deutschen Gegenwartssprache. Zweite Auflage. Berlin: Schmidt.

Hudson, R. (1980). Constituency and Dependency. Linguistics, 18, 179-198. http://dx.doi.org/10.1515/ling.1980.18.3-4.179

Hudson, R. (2004). An Encyclopedia of English Grammar and Word Grammar. http://www.Phon.Ucl.Ac.Uk/home/dick/enc-gen.htm.

Jung, W. Y. (1995). Syntaktische Relationen im Rahmen der Dependenzgrammaatik. Hamburg: Helmut Buske Verlag.

Kreps, C. (1997). Extraction, Movement and Dependency Theory. Ph.D Thesis, London: University College London.

Langacker, R. W. (1987). Foundations of Cognitive Grammar: Volume 1: Theoretical Prerequisites. Stanford: Stanford University Press.

Langacker, R. W. (2008). Cognitive Grammar, A Basic Introduction. Stanford: Stanford University Press.

Maxwell, D. (1995). Unification Dependency Grammar (Draft).

Mel'čuk, I. A. (1988). Dependency Syntax: Theory and Practice. Albany: State University Press of New York.

Mel'čuk, I. A. (2003). Levels of Dependency in Linguistic Description: Concepts and Problems. In Ágel et al. (Eds.), Dependency Grammar from Theory to Practice (pp. 188-229).

Percival, W. K. (1990). Reflections on the History of Dependency Notions in Linguistics. Historiographia Linguistica, 17, 29-47. http://dx.doi.org/10.1075/hl.17.1-2.05per

Schubert, K. (1987). Metataxis: Contrastive Dependency Syntax for Machine Translation. Dordrecht: Foris.

Shaumyan, S. (1987). A Semiotic Theory of Language. Bloomington and Indianapolis, IN: Indiana University Press.

Tesnière, L. (1934). Petite Grammaire Russe. Paris: Henri Didier.

Tesnière, L. (1959). Eléments de Syntaxe Structurale. Paris: Klincksieck.

van Langendonck, W. (2003). The Dependency Concept and Its Foundations. In Ágel et al. (Eds.), Dependency Grammar from Theory to Practice (pp. 170-187).

Van Valin Jr., R. D. (2001). An Introduction to Syntax. Cambridge: Cambridge University Press. http://dx.doi.org/10.1017/CBO9781139164320 